\title{
Weapon-Carrying Among Young Men in Glasgow: Street Scripts and Signals in Uncertain Social Spaces
}

\author{
Chris Holligan' ${ }^{1}$ Robert McLean ${ }^{2} \cdot$ Ross Deuchar $^{2}$
}

Published online: 29 July 2016

(C) The Author(s) 2016. This article is published with open access at Springerlink.com

\begin{abstract}
Our work contributes through a cultural criminological perspective to a contextualised knowledge of street violence and its constructed meanings; uncertainty, familiarity and strangeness in spaces of urban disadvantage as perceived by Scottish white youths are examined. Youth criminal and anti-social behaviour associated with knifecarrying is widely reported and structures political and media discourses which classify street culture. In our article we argue that a particular symbolic construction of social space, as experienced and constructed by weapon-carrying young white men in Glasgow, informs the landscape of violence judged in terms of official statistics and fear of crime. Signal crime theory as a particular type of cultural criminology affords insights about why weapons are carried. Links with a hierarchical codification of consumer culture inform the findings and resonate with the penetration of capitalism in the lives of the marginalised street youth.
\end{abstract}

\section{Cultural Criminology}

Cultural criminology engages with the ontological fragility of late-modernity, structural inequality, uncertainty, and how these haunt the included and excluded, impacting their fear and vindictiveness (Ferrell and Hayward 2014). A politics of meaning-making

Chris Holligan

chris.holligan@uws.ac.uk

Robert McLean

robert.mclean@uws.ac.uk

Ross Deuchar

ross.deuchar@uws.ac.uk

1 School of Education, Youth Justice and Crime Prevention Institute, University of the West of Scotland, Ayr Campus, Ayr KA8 0SX, UK

2 School of Education, Institute for Youth and Community Research, University of the West of Scotland, Ayr Campus, Ayr KA8 0SX, UK 
figures at the heart of cultural criminology and the way in which identities and individuals flow across boundaries of time and space in the 'liquid' world described by Zygmunt Bauman (Ferrell 2013). If social life 'melts into air' this affects the explanatory utility of fixed and rigid categories of meaning (Ferrell et al. 2004). Cultural influence helps construct interpersonal relations and social judgement and it is to the analysis of urban spaces where the marginalised live on the detritus of consumer society that cultural criminology engages and studied the apparent irrationalities of that social space (Cohen 1972). The 'seductions of crime' are explored through a situated lens compassionate to human transaction. As Brotherton (2015) claims transgression is attractive, identity is interwoven into actions that transgress and accompany an existential psycho-dynamic.

We argue that the cultural construction of violence and the sense-making that accompanies weapon-carrying can be interpreted in terms of signal crimes theory whose symbolic interactional pedigree accommodates cultural criminology (Innes 2004). Innes (2004, p. 356) defines a 'signal crime' as "a criminal incident that is interpreted as indicating the presence of criminogenic risk"; that risk belongs with a multi-layered world associated with the street gang and violence (Brotherton 2015). Ferrell (2013, p. 257) states cultural criminology is "designed for critical engagement with the politics of meaning." Meaning refers to contested social and cultural processes through which situations are defined, and individuals, together with their actions, categorised (Ferrell 2013). Brotherton (2015) argues there is an emotional investment in acts of deviance and he identifies interpersonal violence as part of a street gang member's life world, which harbours successions of unpredictable encounters. The "underlife" of the city reflected in Jock Young's recognition of Raban's Soft City (1974), and de Certeau's (1984) spatial structures transgressing private and public geographical spheres, belong with the meanings of these youths' experience. Behind our examination of weapon-carrying we are pursuing the way criminalised sub-cultures construct alternative meanings and respond to signals that 'count' in their elaborated social worlds. Weapon-carrying is associated with street cultures perceived as violent; often marginalisation and conflict is coded in the concept of the gang, to which we now turn, for it is in this situated context that our research participants justify and explain inclinations for weapon-carrying.

\section{Street Culture, Violence and Gangs in Britain}

Brotherton (2015) described how, in the US, a politics of space interconnects with a politics of security. His recognition of this concordance is a theme that pervades our empirical data the meanings of which show an intersection of class and gender that are grounded in urban spaces. Despite the flux and apparent chaos of social life, hierarchies or positioned power that impact the street endure (see Densley 2014, p. 369; Sandberg 2014, p. 600). Bourgois (2003, p. 8) defines 'street culture' as "complex and conflictual webs of belief, symbols, modes of interaction, values and ideologies that have emerged in the opposition to exclusion from mainstream society". Debate rages about whether street gangs in British cities are "shapeless gatherings of peers... or structured groups that coerce 'reluctant gangsters' into their ranks...or the exaggerated...and imaginary creations of academics, police officers, and policy-makers who 'need' gangs in order to justify their very existence" (Densley 2014; Pitts 2008; Densley and Stevens 2015). Hallsworth and Young (2008) argue violent sub-cultures are not necessarily gangs and violence in the street is not necessarily caused by collective gang behaviour, unsurprisingly he calls for an 
interpretive stance towards "violent street worlds" (Hallsworth 2013). In Brotherton's (2015) study there is a de-coupling of violence from his ethnography of the US street youth gang, a perspective that informs the focus of our theoretical emphasis on weapon-carrying, not gang association or membership as such.

A common definition of a weapon is a tool designed or adapted to cause physical harm, but such objectifying accounts overlook the cultural meanings a weapon may represent, a subject we examine later. Brennan et al. (2006) emphasise weapon-carrying behaviours differ in motivation from using weapons in violent conflict indicating the presence of a politics of security which need not entail acts of violence. Palasinski and Riggs (2012) found for teenagers weapon-carrying was constructed as a legitimate response to threat and a means of commanding respect on the street. Knife crime is only partially understood in terms of who carries knives and why (Eades 2006). According to Harding (2012), prevailing cultural norms govern weapon choice and purpose. The threat of violence with a weapon is a method of coercion to facilitate compliance (Kleck 1991), but at the same time it may symbolise resistance and paradoxically additional marginalisation. Fear of physical intimidation can motivate weapon carriers who feel vulnerable (Felson 1996) and members of illicit sub-cultures (Ferrell et al. 2004).

Ilan (2012) advises that the notion of gangs ought to be replaced by the concept of 'street culture'. For Fraser (2013) 'gangs' have existed in Glasgow for decades as territorial and masculinity-associated phenomena (Patrick 1973; Davies 2013) offering temporary, comparatively stable, local meaning and identity to young teenage men facing unpredictable futures in transitions to adulthood in 'liquid' times. Fraser (2015, p. 20) argues "Gang identification is a contextual practice" and a "local articulation of structural processes" and, to reference street culture, it is 'liquid' in Zygmunt Bauman's (1991) orientation, subject to "movement and change" (Fraser 2015, p. 46). The gang for Fraser (2015, p. 123) is an identity experimented through territorial boundaries where "performance of gang activities" is a phase of social development. Cultural criminology has an uneasy relationship with discourse from above, reflective of positivist criminology and associated neo-liberal politics: "problems caused by youths" is a framing anathema to its humanistic politics where gang affiliation is not indicative of a social or psychological pathological deficit. Attention should focus on the "compressed spaces" of their lives to understand gang formation and violence as cultural phenomena that develop in specific ways in response to socially constructed scripts. In that vein both Raban and de Certeau highlight transgression as an underlife of the city, not pathology. Spaces take on meanings in the street which excite, provoke fear and inspire conflict.

Ilan's (2012) focus on the micro-aspects of street culture ties them to meso-level and macro-levels of the social structure; street cultures are "intertwined" with dynamic and fluid processes of social exclusion and inclusion. Street culture, for instance territoriality, unfolds through urban street spaces. Signs of 'defiance' (p. 152-53) empower and simultaneously marginalize street youth, a process Paul Willis (1977) identifies in the oppositional school behaviour of working-class lads whose agency helped lead to cultural reproduction of their class status. Ilan argues that globalised neo-liberal politics deepen inequalities and shape street cultures whilst fostering materialist consumerism and the criminogenic strain. Everyday street culture is, Illan discovered, produced and reproduced in everyday life, creating what he calls a 'street culture spectrum' (pp. 10-11) to frame the social practices of these cultures including violence and 'cool' street attitudes (Dimou 2015). The notion of street capital highlights agency's embedded nature in this microworld and its particular cultural structures whose meanings may frame how weapons and their carrying is conceptualised by codes or scripts utilised by street youth. 
As part of a street-socialized culture, gangs form codes of conduct and behaviour which are shaped, as Ilan (2015) argues, through types of marginalization connected with late modernity. Local oppositional identities characterize these urban street cultures where the moral and legal authority of the state is replaced by the gang; the gang is where "disengaged young people" find protection, welfare, entrepreneurial opportunity and operate "informal spatial monopolies". Resistance in these settings however entrench marginalisation. Gangs for Harding are a "street government" (p. 22) which operates within a distinctive social field with particular dynamics of hierarchical conflict, but in 'liquid times' working-class spaces although fixed in terms of neo-liberal mapping in terms of static definitions of territoriality are diverse and less intelligible. Harding (2012) defines street-capital "as a structured hierarchy supported by a network of inter-woven relationships, both intra-gang and inter-gang, including peers, extended families and neighbours". Gossip, rumour and conversation lubricate type of cultural capital through which signals are processed and also produced for consumption by others. Signals as forms of communication represent cultural phenomena which contain meanings that shape social and individual orientations in violent or potentially violent street cultures. Dynamics of security and threat feature in Fraser's (2013) descriptions of working-class street youth in Glasgow.

Fraser's (2013) participant observations explored the social constructions of teenage white males about their street lives, many of whom admitted to committing violent and anti-social actions and affiliations with their local 'gang'. Fraser argues their 'gang' identity is "fluid and context specific" (p. 981); geographic spaces were a resource they used to create meaning, belonging and identity in an uncertain world to which they felt connected, but also feared what was changing, was new and only partially known. The young men's "street habitus" is inflected at multiple levels, historical, cultural and structural which impact upon individual biography (p. 973). Their marginalization by place, status and class meant their social identities were multi-layered. Place attachment informed their 'gang' affiliation in a landscape where boredom and doing nothing "are central motifs" (p. 977). In this sense there seemed to be insufficient meaning in their lives. Fraser's 'gang' world is intensely compacted socially, culturally and geographically, and for this reason it entraps these youth further whilst seemingly offering solutions to disadvantage and its accompanying "spoiled identity" (Goffman 1986). In order to contribute to a specifically cultural criminology of the street our paper attempts to explore the meanings of weapon-carrying and give voice to a contemporary variant of 'history from below'. To that end our research engages with research participants who are weaponcarrying young men. It is their particular constructions of space, time and their social settings that we endeavour to understand better and, by implication, add to our knowledge about why weapons are carried in the contemporary urban street.

\section{The Research Study}

Scotland ranks first out of 35 OECD countries for serious assault, and twelfth for homicide (Civitas 2012): the homicide rate for males aged 10-29 in Glasgow (Scotland's largest city) is comparable to Costa Rico and Argentina (UK Peace Index 2013); in 2011 knives were used in $11 \%$ of the most violent crimes (Scottish Government 2011). Despite 'frequent and widespread' knife-carrying among gang-associated young men in Glasgow (Bannister et al. 2010), weapon-involved crime in Glasgow has recently fallen by $76 \%$ since 2006/07 and by $14 \%$ between 2013/14 and 2014/15 (Scottish Government 2015). 
However, in spite of this officially estimated dramatic decline in weapon-associated violent criminality, fearful perceptions of criminal violence remain intense (Deuchar et al. 2015). Signal crimes theory judged as a theory of security and insecurity is incorporated at the heart of the attempt to explain this conundrum (Innes 2004).

Our sample of twenty young men were selected on the basis of the following key criteria: they had lived in Glasgow for most of their lives, they had experience of involvement in - or been on the periphery of - gang or street violence or other forms of offending behaviour, and they were at least 16 years of age. Some had convictions for violence, others had served time in young offender prisons, and some had been victims of violent crime. Several have siblings and fathers with a parallel violent life histories and forms of exclusion. They live mainly within communities identified in the $20 \%$ most socially deprived areas of the city (Scottish Government 2012; Scottish Index of Multiple Deprivation).

Our sample shares characteristics, but not ethnicity with Densley and Stevens' (2015) London gang sample consisting of young black people whose lives in a black community are replete with serious weapon-related violence, both as perpetrators and victims. Narrative criminology is consistent with the fundamental premise of cultural criminology: stories contribute to the production of social and cultural identities (Sandberg 2010, 2014). We are influenced by narrative analysis which affords sensitivity to social and cultural meanings. The cultural scripts of our interviewees unfold through vernacular stories and particular street socio-linguistics (Bauer 1996). According to Sandberg (2010 p. 461) "interviews are an effective way to reveal offenders' repertoire of narratives" and there are a "multitude of stories present in a social context".

Recruiting our sample took several weeks during which process we were supported by youth and street workers attached to outreach initiatives in Glasgow. Through their kind brokerage we were able to approach the young men at these venues and build rapport, initiating informal discussions with relevant young men and outreach workers regarding the nature of the study and seeking informed consent to participation, prior to interviewing the young men there. We recognise the difficulties associated with accessing such 'hard to reach' populations (Bhopal and Deuchar 2016). The researchers themselves were at ease in this context, having conducted research with offenders in prison and on the street in previous years. One member of the research team was brought up in the areas from which our sample is drawn. Through that informal work and biographical experience we had learned how to frame questions without provoking defensive or other barriers to our communication. Following interviews with six participants lasting about $1 \mathrm{~h}$ we widened the sample by a 'chain referral' sampling method commonly used in the field studies of gangs (Densley and Stevens 2015).

The design of the interview schedule aimed to invite the participants to talk about times and situations that stimulated a feeling of risk, danger, fear and conflict, and that may have led them into violent or other offending behaviour accompanied by weapon-carrying (Holloway and Jefferson 2000). Interviews were recorded and transcribed for analysis; data was anonymized and the participants were informed. Overarching themes were identified in the context of critical perspectives on youth violence, masculinity, risk and fear of crime and we utilised elements of a grounded theory approach to 'street scripts' (Charmaz 2006). The three narratives resulting from our analysis are set out in Table 1: the stories people tell, their linguistic register and choice of lexicon help us to understand values, identities, culture and communities. Cultural criminology focuses upon situations of sub-cultural mediated constructions of the human construction of meaning (Ferrell 2013). The 
Table 1 Cultural Structures and Settings
Places

Fights

Weapons
Life on the estate and perception of risk

Arming oneself for pre-emptive battle

The chib, the jinjie or the blade

structures and associated settings in Table 1 arose from the meanings we identified from our interviews using narrative analysis.

\section{Thematic Narratives}

\section{Places: Life on the Estate, and Perception of Risk}

Deuchar (2009) noted ambivalence in the attitudes of young people in these largely homogenous working-class places where our own study was conducted, some seeing them as 'shit holes' whilst nevertheless feeling affection for them. Such emotional contradiction echoes with the ontological fracturing that is a defining feature of a fragile late-modern world. This existential splitting or division in the emotional belonging of the self recurred in our data. Al's comment in the first extract below indicates belonging and sense of territory. It is also a community as he describes it - "am here amongst your own". By implication another meaning of "place" is class status. He knows where he fits in this "rough" culture, but his script does not itself give an explicit class analysis. In the next extract Rydo is aware of being negatively categorised through the signal of his voice and associations with a stigmatizing reality TV show that manufacture a meaning for his identity handed down from outside his area:

Aye it's kind of rough but you know the place mate, grew up around these parts so am here amongst your own. - Al

They hear your accent and know you're fae a scheme, they pure make you think you're a bad egg man. You know what I mean ... them shows like 'The Scheme' [a reality TV series following the lives of families in socially deprived communities in Scotland] ... don't make it any better ... people actually watch them shows and think everybody that lives in these places is like that, pure junkie [drug addict] central. Rydo

They attribute stereotypic processes to voices_- "your accent"-and places_- "fae a scheme" - concluding a marginalisation with "you're a bad egg man". The interchange "you know what I mean" seeks a validation and recognition of the way structural processes encode them as being 'other'. The affective meaning of this 'underlife' is of a place where inhabitants feel subjected to its powerful othering of them. The television image maps their existence as undeserving and marginal, while the circulation and consumption of this visual medium 'organises' psychic hierarchies and interpersonal status. The physical quality of their environment and their sense of loss as housing stock was demolished and replaced by new buildings, pervaded their oral accounts; the spatially concentrated lives described by Fraser (2015) which fostered place attachment and belonging are mentally re-configured in both intelligible and contradictory ways through a particular cultural construction of media projections of community. 
Despite their place attachments, noted by Sandberg, these young men also perceive their housing schemes through layers of physical risk: their perception of dangers and conflicts are impregnated with tensions related to substance abuse and the creation of street revenue. In response they feel the need for personal protection:

You canny go about yourself or other young teams or junkies would rob the trainees [trainers, sports footwear] right aff your feet. That's why you always carry a tool [weapon] or go about with your boys. - Billy

Being in a group gives him a sense of security, but in consequence he becomes an enemy too. His choice to carry a weapon or to travel in a group reflects his social construction of the streets he frequents. The trope of the 'team' occurred often in our conversations with the participants and offers a more positive resonance compared with the term "gang." Its positive links with football and co-operation helped them to avoid the criminal justice classification connected with the term 'gang', but such split meanings force contradiction on the psyche, as the anti-social sub-culture co-exists with the prosocial notion of team.

These young men subvert language to avoid arrest on the street. That "other young teams" may pose a threat suggests social spaces are replete with risk, uncertainties and hostility. Billy's reference to "rob the trainees right aff your feet", while hyperbolic in rhetorical terms, allows us to tap the physically embodied kind of threat as perceived intrusion and invasion of intimate space. His potential loss of trainers literally impedes his agency.

Cultural significance lies in Billy's reference to weapon-carrying rather than to using this weapon to injure and incapacitate. His choice of the term 'tool' is another example of coining of to manufacture a different world and implies that requires the annexation of middle-class meanings. If this commitment to weapon-carrying is public knowledge in the streets within the social orders young men like Billy encounter and anticipate, it disrupts "the appearances of normality and thus social order" (Innes 2004, p. 341); as Innes (2004), citing Goffman (1972), recognised, it provokes forms of street navigation where there is omnipresent scanning for 'signs of alarm' and 'signs for alarm'.

Community members and the local police used the universalistic lexicon of 'the gang' to refer to these young men and therefore signal to others a classification of their danger. So this narrative theme operates through contrasting and conflicting conceptual boundaries. Boundaries are marked by signals of territorial ownership, dimensions also reported by Fraser $(2013,2015)$; such markers include graffiti, street furniture and references to the names of tenement buildings where some of the young men live. And they are denoted, as described, by alterations to conventional vocabulary. Threat extends to intimate social spaces:

I got into a fight wi' ma neighbour a while back aboot noise ... always keep a chib

[Scottish parochial for a street weapon] just behind the door in case the cunt's a psycho or what, ye know what I mean? - Bobby

Social cohesion is unsettled and street life can be safer than home. The conflict in this compressed social space is "aboot noise" indicating lives shared in aural terms, and denoting a lack of consensus about acceptable sound levels; it does not have to be differentiated into types of noise for it to disrupt relations and boundaries. The "noise" is an intrusion which disrupts the peace and privacy of the neighbour's aural space and brings about a fraught interpersonal encounter. Billy does not perceive a potential caller as necessarily normal, fearing he might instead be "a psycho or what". Following Zygmunt 
Bauman (1991) there is estrangement amongst residents in close proximity. The neighbour is 'known' through the meaning given to the abstract signal of a noise which has become a kind of language. As another young man explained:

'They [potentially threatening youths from other scheme] all know who their own are. I'm no' fae there, would defo [definitely] get ID'd [asked for ID] and probably knifed.' - Hendi

Being in a 'gang' is scheme-related in Glasgow. Identities are questioned, not trusted and must be validated or else rejected through violence. Hendi constructs this territorial culture and its rites of safe passage. The fear dimension of their lives is sometimes informed by the social constructions they place around community hearsay:

Naw, no personally but always hear of people getting done in and shit. - Hendi

The research participants construct fear signals as personally relevant and trustworthy. Street knowledge circulates through these tokens of apparent authority which guide navigation of physical spaces. Bodily appearance and personal clothing are more tangible signals of identity and territorial status, which are also a source of the street knowledge connected with avoiding personal injury:

Yeah, I have to admit if I was passing a team a' youngsters in another area, wearing the hoodies, the Berghaus [Jacket type associated with gang members], I would feel a bit intimidated, I 'hink.' - Al

Cultural consumption follows conformity to a brand of jacket which signals social affiliation. Urban mythology and moral panics, as Innes (2004) argues, are intelligible irrespective of any putatively objective crime statistics. These young men actively engineer a particular culture whose transparency to outsiders is likely limited, and in that way they seal themselves from the middle-classes, whilst having to re-create meanings for the items, lexicon and clothing they use to manufacture a different social geography. The next narrative conveys a form of their social resistance to the cultural imaginings described.

\section{Fighting: Arming Oneself for Pre-emptive Strike}

During interviews our sample expressed a 'protest masculinity' (Connell 2005; Carlsson 2012). By presenting the self as 'tough' and 'aggressive', and displaying heterosexual affiliations they help create a street world and identity (Holligan and Deuchar 2015), 'managing' the interactional order and presentation of self in terms of the situated meanings described earlier. This social space is a traditional masculinity. Words, expressions and clothing instantiate a manly connotation which violent street capital reinforces and validates as mainstream:

Last guy to try and stare me doon man, fucking ended up in hospital. - Derek

I never cry. Never in front of people. No chance. They would think you [speaking about himself]) were a little bitch. - Del

Growing up in the scheme, guys only respect you if you can fight, pull burds [women], or play good footy. - Mop

Guys definitely think more of you if don't let cunts fuck about wi' you. - Rav 
A denial of emotional life marks out Del's place in the street's masculinised hierarchy, but these social ties appear provisional and contingent on the successful achievement of cultural norms. The anonymous reference to "last guy" and "in hospital" reminds us of Ilan's (2012) characterisation of street culture where, in that liquid urban world, warmth of belonging and place attachment has dissolved, street life is more diffuse, spanning different areas, and the local area is no longer a safe haven. Ilan's Irish youths roam Dublin's city streets building new acquaintances; strangers are encountered routinely and relationships negotiated based on signals of shared meanings; "never crying". The theft of motor-cycles and other powered equipment by male youths in Ilan's Dublin conveys a performing masculinity that hurts others.

Heterosexual power is itself one of the dimensions of this Glasgow street culture. Mop refers to 'pulling birds', a lexicon of theft, for pulling is assertive and acquisitive, that conjures a need for violence and grants power to the male subjugator over the frail female. In the alienated and traumatised social world of the Dublin street youth neighbours and local community residents are suspect rather than supportive. We find this thread in Glasgow: references to weapon-carrying by Bobby and Joe resonate powerfully with the collapse of solid modernity and its replacement by the politics of immigration and drug consumption; this social space resonates with the fractured liquid urban as theorised by Ilan (2012).

You canny trust the people aroon [around] here. I stayed in [Glasgow area] and knew everybody, but this place is junkies, immigrants, and that sorta people.... always keep a chib. - Bobby

Ma younger brother would like pure hang about the streets to all times a' night. I know he used to carry a bat about if he was going down the scrappy [area where youths congregate in this housing estate] at that time a night on the weekends, "cause all the addicts and that, that hang about. - Joe

These cultural constructions privilege danger in periods of darkness, specific locations and an urban milieu dense with social dislocation. Addicts and immigrants do not belong to their street world, but haunt the physical spaces. Like youths in Ilan's Dublin, many in our sample had been victims of violent crime and bore scars from knife wounds. They used the term 'troops' to militarise themselves, configuring social space as a battleground. They consumed media imagery about gang violence and associated fashions, but they objected to their othering by "people" commenting, for example:

'Cause I wear hoodies and the old slashers [certain types of skip caps associated with promoting a visual display of being willing to engage in violence] now and then ... people think I'm dodgy n'all, aye. I just keep myself to myself but cunts just think that 'cause the pictures they see in the papers of NEDS, that's all. - Rav

Cause of ma age and how I'm dressing [wearing tracksuits], people all think 'there's another NED oot to cause trouble'. - Hendi

I'm not even in a gang but people where I stay think I am because we go about in a group at the swings. - Len

You know the papers are always like that ... printing that stereotyped shit. If someone wears a hat he's a bam. If someone's got a Berghaus on he's got a blade down his trousers. - Rav 
These extracts demonstrate an intense awareness of a mainstream society which intrudes into their identity and esteem, provoking defensiveness. Awareness of clothing types encourages Rav to classify perceptions of others about him as negative - "dodgy n'all" - and distances members of the mainstream as alien enemies whom he aggressively demeans - they are mere "cunts." The geographic compression identified by Fraser (2015) is psychological and social - hostile attitudes to others reinforce and deepen a sense of their status as participants of a marginalised and disrespected sub-culture. In this street culture clothing signals street capital and communicates to "people" who in this instance are an older and ignorant generation:

The auld yins think you're up to trouble when ye don't even bother with them. Other teams though might attack ye cause how ye dress. They all think, 'aye he's one of them' [from a rival territory] cause you've got a hat on your heed or something. That's how I never leave here without a few of my boys or least a tool eh? - Hendi

Hendi attributes to another generation of residents, the "auld yins", a moral disposition. Their judgemental frame, he believes, blames him for "trouble". Such a cultural classification of the social order of chronological age locates these street youths as part of the mainstream despite the contempt in which they hold it. For Bobby society has changed and today weapon-carrying is essential:

Need to carry [a weapon] nowadays man, don't you know Glasgow's the stab capital of the world? - Bobby

The trope of "the stab capital of the world" works to justify his weapon-carrying. He reconfigures a circulating discourse about the status of his city which normalises his weapon-carrying. His weapon-carrying endorses a citizenship type: he is a bona fide stab capital citizen. Throughout this narrative the research participants are constantly utilising cultural justifications for their decisions. Their analysis of the social foregrounds layers, tensions and the use of selective rhetoric to persuade. It is this cultural distillation of the social that informs and creates the need for a scientific masculinity connected with weapon design and effective choices.

\section{Weapons: The Chib, the Jinjie and the Blade}

Weapons are themselves worthy of cultural attention. Several are improvised and can be constructed rapidly or deconstructed with equal velocity as situations on the street present. Off-trade glass is a common weapon used by male young offenders in Scotland in violent assaults (Forsyth et al. 2010): around $66 \%$ of his Polmont prison sample used weapons, of which knives were the most common, followed by bottles. Forsyth et al. concluded that, unlike knives, bottles were seldom 'carried' and were instead easily available during the mainly alcohol-related violent incidents. This street-culture includes knowledge about useful resources and where they are acquired. Forsyth et al. found on-trade glass (from inside pubs and night-clubs) never mentioned by his youth group of thirty prisoners, indicating they 'armed' themselves in the street from off-trade alcohol glassware, or simply adopted it opportunistically to fight and defend themselves.

Fearful perceptions of being assaulted pervade our participants' ideas about the social, and several have friends and siblings in Polmont. Critical self-evaluations of their own physical capacity led some into weapon-carrying, but flexibility matters; as Don reasoned being a target requires extra precautions, hence his choice of blade to supplement a powerful physique: 
I'm over $6 \mathrm{ft}$ and weigh 18 stones so I use my fists mastly but if someone's after me that's dodgy I would probably carry a blade aroon' - Don

Don estimates several forms of defence can be required, demonstrating that effective street capital embraces knowledge of defence, estimations of the strength of enemies and the capacities of weapons afford. In line with the Forsyth et al. results, our sample named knives as their preferred weapon; but in practice weapons are often constructed with ingenuity from easily available banal objects which evade the criminal law - "the jail":

You're like 'what tae take eh, the chib, the jinjie [juice bottle], or the blade ... can get away with carrying a bottle ... but the blade would get ye the jail so that's a defo' no', mate - Hendi

I used tae have this rolling pin man wrapped in barbed wire with a few nails hinging oot it - Bobby

Ever seen that movie 'Scum' ... gave me the idea tae carry about a sock wi' a brick in it. You can dismantle it rapid n'all and no' get charged aff the polis [police] Billy

Pragmatism informs weapon choice and design: a sock and brick were harder to classify as illegal weapons. Few of our participants had experienced being confronted with a knife, but fear signals projected across their street culture are picked up by their cultural frames. Being knifed may be a threat, but in reality weapons are typically everyday objects used to further assaults, as Hugh acknowledged:

People would always say you're getting stabbed and shit but other than one guy pulling out a set of nunchucks [martial arts equipment] it's only ever been bottles or bricks really usually - Hugh

Weapons are hierarchically ordered within the social hierarchies of the street with the law helping to create an opportunistic pecking order of potential force. A weapon is a means of protection; it bolsters and protects a street mentality governed by a pragmatic analysis of the cultural construction of an uncertain social space. The next two extracts demonstrate a serendipitous feature of violence where threat is neutralised by the use of readily available solid objects; the unpredictable transformation of bricks and cheap wine bottles into weapons undermines certainty and challenges the politics of security:

See tae be honest man most times I just grab a brick - Bobby

Usually when I fought I would have been drinking so would put the bucky [Buckfast tonic wine] bottle over the wideo's ['wide' boy's] heed - Derek

Sites of conflict shaped the decision-making and opportunities in terms of the weapon they might employ. In the following domestically-located conflict the sense of entrapment by place contributed to seeking a knife - micro-structures of weapon choice arose from the emotional encounter in this space where even during period of rejoicing and togetherness violence may appear suddenly. Don is faced with "kitchen devils" so takes "a blade" to equalise the odds in terms of weapon capacity:

Been in a few brawls in empties [house parties]. Definitely grab a blade then. No wanting stuck inside and shit goes down, you're trapped and pricks have kitchen devils - Don 
This type of working-class masculine space figures in other studies (Hallsworth 2013; Bannister et al. 2010). The volatile nature of housing schemes spaces that are the material base of the culture we have explored leads these youths into justifying weapon-carrying as representing not fashion but a need. Denzo explains why he carried a hammer "just in case" and hearsay crime signals are referenced again:

Ma first charge came fae carrying an offensive weapon ... had never been attacked or nothing, randomly like, in the scheme but on chance shit might have went down man I carried a hammer ... you would always be hearing a' cunts getting stabbed and shit so fuck that happening ... nah fuck that, worth the charge. - Denzo

The politics of insecurity resonate with his construction of space - "a hammer" is a compromise, providing a sense of protection and legal to carry. Hearsay recurs as a source of knowledge about dangers, contributing a signal that shapes the rendering of the symbolic construction of social spaces and alerts street youth to risk and danger, and how best to react.

\section{Concluding Discussion}

A limitation of previous research into street violence is that it neglects to pursue the constructions held by youths who carry weapons. By coupling that focus in this paper with signal crime theory (Innes 2004) our contribution accommodates a cultural criminological perspective that helps to advance our grasp of violent street worlds from the perspective of participants including their historic linkage with gangs. Our data brings into view objects and events which are otherwise ordinary, but which become imbued with other microsociological meanings giving rise to violent posturing, hostile appraisals and layers of marginalisation. Jackets, bottles, nunkchucks, blades, hoodies are some material objects which contribute to a type of actor-network which seems to shrink the social space and engender vulnerability. Innes (2004) social semiotic analysis illuminates greatly these phenomena, and allows some re-conceptualisation of other studies of this field.

The analytical perspective adumbrated within a cultural criminological vision alerts us to how the public understanding of crime and associated threat is "imbricated in the wider symbolic construction of social spaces" (Innes 2004: 336). Our data helps make visible the sources of these constructions which contain temporal, spatial and historical dimensions. Phenomena judged as warning signals are relative to the webs of significance that constitute the street scripts of the young men. A limitation with Innes's (2004) theoretical ontology is that it overlooks the way something banal may function for street actors as a signal that warns them of risk and encourages weapon-carrying. Fear is latent and manifest with its intensity shifting as persons traverse areas and navigate new situations. As Innes (2004) argues, people 'tune' into signal crimes (and events or symbols) in order to estimate risk.

Ilan's (2012) group, known as 'The Crew', are a "fluid youth offending group" who are domiciled "in a social housing estate", a situation shared with our sample. Similar to others such as Hallsworth, instead of using "gang discourse" to designate them and situate them in the classic gang world of the US during the solid modernity of Fordism and the fixed special spaces of belonging and gang culture, Ilan characterises their street culture in terms of the notion of "redivision in space" to denote mobility across the territory of the urban through the affordances of bridging social street capital, where acquaintances and 
alliances are formed and re-formed. Their acquisition of social capital in terms of signal crime theory represents adjustment to risk.

Akin to our sample in the 'liquid' world he imputes to the contemporary urban, Ilan's (2012) youths construct and re-construct self-defining narratives to navigate and define a social space and its order. With justification he concludes this social group have a "precarious relationship to their place and community of residence" (Ilan 2012, p. 12). The hostile interactions they and their families have with neighbours challenge the idea of a safe and welcoming territorial space, a phenomenon connected with late-modernity. Our participants, too, were uneasy with neighbours and were prepared for them to turn violent; they had experienced personal trauma, they had engaged in criminality, they been victims of serious assault, some had parents who had been murdered or incarcerated. Being victims and engaged in street lifestyles does, according to Innes (2004), impact on their calibration of risk and therefore weapon-carrying decisions. Strands of the street culture depicted by Anderson (1999) surface, as some sections of the community actively avoid them, and even within their own street group they found no "fixed and stable community of residence" (Ilan 2012, p. 12) which is likely to have engendered his discovery that there was only a weak association with any "interstitial conflict" (p. 15). That type of conflict does not necessarily, then, characterise a street culture when it is other than territorial, in the traditional fixed or 'solid modernity' meaning accorded to it, for example, by Patrick (1973), as the attitudes we examine through our final narrative about the social orientation of weapon-carrying indicate. If street culture is not territorially nuanced, and there can be only a tenuous cohesion among gang affiliated youths themselves, it is fair to conclude that danger and risk is intensified for youths associated with fractured social bonds.

As Fraser (2015) reports, leisure in Glasgow has evolved and is now centralised in the city centre. The young men is his study conducted their street lives locally in neighbourhoods familiar to them and where they claim to have experienced belonging, spatial identity and safety. His emphasis on the heterogeneity and multiplicity of gangs is foregrounded through concentration on the "lived experience of young people in specific contexts" (p. 3). The recognition that gang identities are hard to separate from other peer associations (Batchelor 2009) valorises processes of informal friendship networks, whose boundaries are porous, where passage of time and changes of membership causes subtle transformations that will interfere with the longevity of their social connections as postindustrial cityscapes evolve (Aldridge et al. 2007). Our research participants held split attitudes to nightlife and places for the conduct of social life: positive attribution was given to nightlife, but as it was in the centre of the city and expensive it lay beyond the lives they lived in neighbourhoods within housing estates.

According to Innes (2004, pp. 335-336) fear of crime stultifies, working to interrupt the flow of routine culture, and promoting "conditions under which more serious types of offending proliferate". Story and rumour of weapon-carrying contained within selfdefining narratives, including conflict over 'noise', collectively construct the symbolic nature of the social space these young men appear routinely to construct and encounter as material and mental realities. The 'noise' conflict would for Innes's (2004) be a "warning signal". Street attire is for older generations a different warning signal with threatening potency. Their street life as weapon-carrying youths manifests fear as situated in weapon types, places, biographies and beliefs. Signals, as Innes (2004) notes, need not be criminal incidents, and, we conclude, non-criminal signalling succeeds because histories of battles and feuding confer upon it a localised semantic efficacy. The sample constantly attuned their conduct to react to their interpretation of situations which to others may appear innocent or irrelevant; 'public place' is not where they feel safe as gestural cues from 
others can communicate the need for flight or self-defence; alertness is essential to read the 'informing signs' which indicate relationships for co-mingling or conflict (Goffman 1972, 1986). Our study of a culturally constructed street life of young men discovered their vulnerability and posturing. The elaborate interpretations they impose on the street engender paranoia in a psychic world that is unsettled, confrontational and yet inclined towards camaraderie. Their agency is expressed in their mode of resistance to the threats and dangers they construct as ever-present, but that wary temperament shifts them towards a marginalised identity which their weapon-carrying cements.

Open Access This article is distributed under the terms of the Creative Commons Attribution 4.0 International License (http://creativecommons.org/licenses/by/4.0/), which permits unrestricted use, distribution, and reproduction in any medium, provided you give appropriate credit to the original author(s) and the source, provide a link to the Creative Commons license, and indicate if changes were made.

\section{References}

Aldridge, J., Medina, J. \& Ralphs, R. (2007). Youth gangs in an English city: Social exclusion, drugs and violence. ESRC RESO00-23-0615. Swindon: ESRC.

Anderson, E. (1999). Code of the street: Decency, violence, and the moral life of the inner city. New York: WW Norton.

Bannister, J., Pickering, J., \& Batchelor, S. (2010). Troublesome youth groups, gangs and knife carrying in Scotland. Edinburgh: Social Research, Scottish Government.

Batchelor, S. (2009). Girls, gangs and violence: Assessing the evidence. Probation Journal, 56(4), 399-414.

Bauer, M. (1996). The narrative interview: Comments on a technique for qualitative data collection. London: London School of Economics and Political Science.

Bauman, Z. (1991). Modernity and ambivalence. Cornell University Press.

Bhopal, K., \& Deuchar, R. (2016). Researching marginalized groups. New York: Routledge.

Bourgois, P. (2003). In search of respect (2nd ed.). Cambridge: Cambridge University Press.

Brennan, I. R., Moore, S. C., \& Shepherd, J. P. (2006). Non-firearm weapon use and injury severity: Priorities for prevention. Injury Prevention, 12, 395-399.

Brotherton, D. C. (2015). Youth street gangs: A critical appraisal. London: Routledge.

Carlsson, C. (2012). Using 'turning points' to understand processes of change in offending. British Journal of Criminology, 52, 1-16.

Charmaz, K. (2006). Constructing grounded theory: A practical guide through qualitative analysis. London: Sage.

Civitas (2012). Crime policy, fact and comment. http://www.civitas.org.uk/crime/comments.php. Accessed December 7, 2015

Cohen, S. (2002 [1972]). Folk devils and moral panics. London: Routledge.

Connell, R. W. (2005). Masculinities. Cambridge: Polity Press.

Davies, A. (2013). City of gangs: Glasgow and the rise of the British gangster. London: Hodder and Stoughton.

de Certeau, M. (1984). The practice of everyday life. Berkeley, CA: University of California Press.

Densley, J. A. (2014). Book Review: S. Hallsworth: The gang and beyond. Criminology and Criminal Justice, 14(3), 368-374.

Densley, J. A., \& Stevens, A. (2015). 'We'll show you gang': The subterranean structuration of gang life in London. Criminology and Criminal Justice, 15(1), 102-120.

Deuchar, R. (2009). Gangs: Marginalised youth and social capital. Staffordshire: Trentham Books Limited.

Deuchar, R., Miller, J., \& Barrow, M. (2015). Breaking down barriers with the usual suspects: Findings from a research-informed intervention with police, young people and residents in the West of Scotland. Youth Justice, 15(1), 57-75.

Dimou, E. (2015). Book Review: J. Illan (2015) Understanding street cultures: Poverty, crime, youth and cool. Nordic Journal of Youth Research, 23(4), 373-375.

Eades, C. (2006). Knife crime: Ineffective reactions to a distracting problem? A review of evidence and policy. London: The Centre for Crime and Justice Studies.

Felson, R. B. (1996). Big people hit little people: Sex differences in physical power and interpersonal violence. Criminology, 34(3), 433-452. 
Ferrell, J. (2013). Cultural criminology and the politics of meaning. Critical Criminology, 21, $257-271$.

Ferrell, J., \& Hayward, J. (2014). Never boring: Jock Young as a critical criminologist. Crime Media Culture, 10(3), 179-190.

Ferrell, J., Hayward, K., Morrison, W., \& Presdee, M. (2004). Cultural criminology unleashed. London: Glasshouse.

Forsyth, A. M., Khan, F., \& McKinlay, W. (2010). The use of off-trade glass as a weapon in violent assault by young offenders. Crime Prevention and Community Safety, 12(4), 233-245.

Fraser, A. (2013). Street habitus: Gangs, territorialism and social change in Glasgow. Journal of Youth Studies, 16, 970-985.

Fraser, A. (2015). Urban legends: Gang identity in the post-industrial city. Clarendon Studies in Criminology. Oxford: Oxford University Press.

Goffman, E. (1972). Relations in public: Micro-studies of the public order. New York: Harper Colophon.

Goffman, E. (1986). Stigma: Notes on the management of a spoiled identity. New York: Touchstone Book.

Hallsworth, S. (2013). The gang and beyond: Interpreting violent street worlds. Basingstoke: Palgrave Macmillan.

Hallsworth, S., \& Young, T. (2008). Getting real about gangs. Criminal Justice Matters, 55(1), 12-13.

Harding, S. (2012). A reputational extravaganza? The role of the urban street gang in the riots in London. Criminal Justice Matters, 87(1), 22-23.

Holligan, C., \& Deuchar, R. (2015). What does it mean to be a man? Psychosocial undercurrents in the voices of incarcerated (violent) Scottish teenage offenders. Criminology and Criminal Justice, 15(3), 361-377.

Holloway, W., \& Jefferson, T. (2000). Doing qualitative research differently. London: Sage.

Ilan, J. (2012). Street social capital in the liquid city. Ethnography, 14(1), 3-24.

Ilan, J. (2015). Understanding street culture: Poverty, crime, youth and cool. London: Palgrave MacMillan.

Innes, M. (2004). Signal crimes and signal disorders: Notes on deviance as communicative action. British Journal of Sociology, 55(3), 335-355.

Kleck, G. (1991). Point blank: Guns and violence in America. New York: Aldine De Gruyter.

Palasinski, M., \& Riggs, D. W. (2012). Young white British men and knife carrying in public: Discourses of masculinity, vulnerability and protection. Critical Criminology, 20, 463-476.

Patrick, J. (1973). A Glasgow gang observed. London: Eyre Muthuen.

Pitts, J. (2008). Reluctant gangsters: The changing face of youth crime. Devon: Willan.

Raban, J. (1974). Soft city. London: Hamilton.

Sandberg, S. (2010). What can 'lies' tell us about life? Notes towards a framework of narrative criminology. Journal of Criminal Justice Education, 21(4), 447-465.

Sandberg, S. (2014). Book Review: S. Hallsworth: The gang and beyond. Punishment and Society, 16(5), 598-639.

Scottish Government. (2011). Crime and justice survey: Main findings. Edinburgh: Scottish Government.

Scottish Government. (2012). Recorded crime in Scotland, 2014-1 Scottish index of multiple deprivation. Edinburgh: Scottish Government.

Scottish Government. (2015). Knife crime in Glasgow continues to fall. Edinburgh: Scottish Government. http://news.scotland.gov.uk/News/Knife-crime-in-Glasgow-continues-to-fall-1e8c.aspx. Accessed November 27, 2015.

UK Peace Index. (2013). Exploring the fabric of peace in the UK. Institute of Economics and Peace, Report 20 .

Willis, P. (1977). Learning to labour. Aldershot: Gower. 